\title{
CROSS-PROVINCIAL POLICIES IN CANADIAN ART EDUCATION
}

\section{Laurie Baxter}

The concern of this study is educational policy, more specifically the construction of policy for instruction in the visual arts in the various provinces of Canada. Recent literature has emphasized the role of policy and decisionmaking in the arts. MacGregor (1985) recognizes that "...educational decisionmaking policies dominate and control curriculum considerations, rather than the other way around." The intention underlying the discussion is to isolate those certain common objectives which are manifested in the various educational policies governing art education in $\mathrm{C}$ anada. It will be suggested that these common elements reveal an existing consensus among $\mathrm{C}$ anadian art educators -a consensus upon which a national policy for education in the visual arts might readily be constructed.

Constitutionally, jurisdiction over education in Canada is assigned exclusively to the ten individual provinces. The Department of Education for each province mandates the production of curriculum materials, selects committee members and develops the basic philosophies of curriculum programming. The provincial governments appoint directors of curriculum who in turn assign members of their staffs to the task of administering one or more subject areas. What occurs with some regularity in these educational bureaucracies is that promotion of the arts is attenuated relative to those areas of study which are viewed as the 'core subjects'. A second result of this constitutional arrangement has been the almost total lack of communication and idea sharing in the arts at a national level.

In preparing for this study three factors are taken to be given: firstly, that with ten educational bureaucracies at work in similar institutional and cultural environments, there will inevitably be a measure of commonality; secondly, that a cross-fertilization induced by a sharing of ideas nationally would serve to enhance the art education policies of each of the provinces; and, thirdly. that the creation of a national policy would offer each of the provincial educational authorities a degree of consensus that will enhance policy and decisionmaking.

"Canadian art teachers manage to maintain several productive coaxial connections that provide a steady flow of art education ideas and images. These connections run north and south, east and west, and span the Atlantic and Pacific oceans (Gray, 1984)." Ideas, attitudes toward educational practices, and the various language and cultural groups across the nation are among the factors which affect the development of curriculum and will form the character of a national policy for the arts. MacGregor (1984) commented in an article on Canadian art educators that "What emerges when we compare notes, transprovincially is that given their random origins and piecemeal development, provincial and even local differences do not seem as pronounced in terms of content as they are in terms of teacher availability, the kinds of facilities that exist to house art programs and the amount of support given the arts within the 
community."

Apparent in policy and decision-making is the amount or kind of exchange of knowledge and communication which exists between the different Departments of Education in the similar business of curriculum planning and implementation in the visual arts. In a study of school policy conducted in the United States on the effectiveness of educational policy. Wirt (1976) discussed the desirability of interrelationships among the states "... Knowledge of these relationships seems a basic requisite to policy making at the national level and to scholarship, either in comparative studies or in case studies. The larger view is necessary if one is to understand either national patterns in this matter or the significance of a single study."

Lastly, there is the problem of departmental staff formulating policy with little or no understanding of the distinctive body of content derived mainly from the history and theory of art education. The allocation of instructional policy in the arts as stated earlier is subject to numerous political circumstances, which have not always resulted in the best person's being appointed to the task. According to Smith (1984) "...policy for art education has been deverted from its course by prevailing federal winds, funding patterns, and philanthropic caprice."

This cross-provincial policy comparison of instructional goals in the visual arts seeks to formulate through a Delphi Survey method a national consensus of policy for the visual arts. The creation of a national model to which the provinces could then attach specific clauses or variations to accommodate local priorities, would serve the course of advocacy for art education, specifically with school boards and educational administrators. This model may also provide a well articulated philosophy for the uniqueness of Canadian art education. Finally it is to be hoped that it will serve as the construct for a continuing improved communication and expanding interrelationships among policy makers and art educators across Canada.

This study seeks to elicit and rank responses to three questions. These are: 1. To what extent does a consensus exist in the policy statements for instruction in the visual arts as mandated by each of the ten provinces in Canada? 2. Among the policy makers from the individual provinces, what order of priority can be formulated from the policv statements? 3. From such a ranked list can a national model for policy be constructed?

The methodology employed for this study is a Delphi method; more specifically, the policy Delphi method. The policy Delphi provides an organized method for correlating views and information pertaining to a specific policy area. The panel of provincial policy makers for the visual arts will pursue the topic through three rounds of questionnaires until a clear indication of the group's opinions and attitudes emerges. When consensus is obtained on an issue, it is dropped from further exploration and reappears only in the summary document. When polarization of views occurs the study monitor can design questions to probe differences. A reduction of the responses will be performed using descriptive statistics based on importance ranking of items by participants. The Importance Scale Definitions are: 
$1=$ Very Important: First order priority

2 = Important: Second order priority

3 = Moderately important: Third order priority

$4=$ Unimportant: Low priority

The study is currently being conducted.

\section{REFERENCES}

Gray, J. (1984). Coaxial connection: Art education in Canada. Art Education, $36,6-8$.

MacGregor, R. N. (1984, October). You're old enough to drink, but what are you going to do with your life? Paper presented at a meeting of the Canadian Society for Education through the Arts, Winnipeg, Manitoba.

MacGregor, R. N. (1985, April). Policy making and policy changing. Paper presented to the meeting of the National Art Education Association, Dallas, Texas.

Smith, R. A. (1984). Formulating a defensible policy for art education. Theory into Practice, $x \times 1114,273,279$.

Wirt, F. M. (1977). School policy culture and state decentralization. National Society for the Study of Education, 76, 165-187. 